\title{
Computer Based Screening of Selected Phytoconstituents from Cyperus Rotundus Linn. Against 5 a Reductase Enzyme
}

\author{
Research Article
}

\begin{abstract}
Nisha S Shirkoli1*, Umashri A Kokatanur², Kishori P Sutar², Shailendra S Suryawanshi
\end{abstract}
\author{
1. Assistant Professor, Department of Pharmaceutical Quality Assurance, \\ 2. Assistant Professor, Department of Pharmaceutics, \\ 3. Assistant Professor, Department of Pharmaceutical Chemistry,
} KLE College of Pharmacy, Belagavi, KLE Academy of Higher Education and Research, Belagavi, Karnataka.

\begin{abstract}
Hirsutism is a condition of unwanted, male-pattern terminal hair growth in women. Electro epilation, laser treatment, intense pulsed light therapy, eflornithine cream, and oral antiandrogen medications are the various allopathic therapeutics have been employed for treatment of Hirsutism. However, a significant number of patients experience discomfort with reported procedures. Cyperus Rotundus Linn. have reported for its anti-androgenic activity effective against Hirsutism disorder. The main objective of present investigation is to screen the selected phytoconstituents of stated plant against $5 \alpha$ Reductase Enzyme. In this study Cyperene, humulen, $\beta$ - selinene, campholenic aldehyde, and $\alpha$-pinene were docked with $5 \alpha$ Reductase Enzyme using PyRx 0.8. Autodock and binding energies were obtained. The present investigation concludes that the molecular docking analysis of selected phytoconstituents with $5 \alpha$ reductase enzyme shows good interaction. The binding affinity of Humulen is higher than others whereas campholenic aldehyde showed lowest affinity amongst all other constituents. Further studies need to be performed at laboratory level to support results of computational screening of present investigation.
\end{abstract}

Key Words: Cyperus Rotundus Linn., Hirsutism, 5 a Reductase, Molecular Docking, Binding Affinity.

\section{Introduction}

Androgen hormone is the one whose presence determines the growth of sexual hair (androgenic hair). Hair in androgen-sensitive follicles is vellus puberty. After puberty due to increase in the levels of androgen, vellus follicles in specific areas develop into terminal hairs (larger, curlier, and darker, hence more visible) and become sexual hair follicles (1-3). Hirsutism is a condition of unwanted, male-pattern terminal hair growth in women. Hairs appearing in Hirsutism are stiff and dark appearing primarily on the face, chest and back where women don't commonly have hairs. Around $5 \%$ to $10 \%$ of women suffer this condition. Women suffering from this condition may lead to significant psychological distress. Hirsutism condition results from interaction between the androgen level and the hair follicles which are sensitivity to androgen (4).

Androgen group of hormones are activated on target cells by two kinds of proteins: the androgen receptor and the $5 \alpha$-reductase enzyme. $5 \alpha$-reductase enzyme has higher tendency of facilitating transformation of testosterone into Dihydrotestosterone.

\section{* Corresponding Author:}

\section{Nisha S Shirkoli}

Assistant Professor, Department of Pharmaceutical Quality Assurance, KLE College of Pharmacy, Belagavi, KLE Academy of Higher Education and Research, Belagavi, Karnataka India.

Email Id:nishakabbur@gmail.com
It has higher affinity to bind to androgen receptor and is more active than testosterone. In other words, 5areductase acts as an amplifier for required androgen action. There seem to exist two kinds of 5a-reductase involved in sexual differentiation: the 5a-reductase of genital skin which is androgen independent and the enzyme of pubic skin which seems to be androgen dependent. (5).

Nagarmotha is nut grass and botanically known as Cyperus Rotundus Linn. is a noxious weed of vegetable and other horticultural or agricultural crops found throughout India. It is dark green glabrous culms, arising from underground tubers and is a pestiferous perennial weed. As an ancient medicine the rhizomes of nut grass are widely utilized round the world to treat various disorders. Studies on $C$. rotundus and its chemical constituents in the past era have proved analgesic, anti-pyretic, anti-arthritic, anti-allergic, antihistamine, anti-emetic, anti-candida, anti-cariogenic, anti-convulsant, anti-diarrheal, anti-helminthic, antihyperglycaemic, anti-hypertensive, anti-inflammatory, anti-malarial, anti-obesity, antioxidant, anti-platelet, anti-ulcer, anti-viral, cardioprotective, cytoprotective, cytotoxic, gastroprotective, hepatoprotective, neuroprotective, ovicidal, and larvicidal, and wound healing activities (6-9).

Electro epilation, laser treatment, intense pulsed light therapy, eflornithine cream, and oral antiandrogen medications are the various allopathic therapeutics have been employed for this purpose (10). Since 1996 Laser treatment have been used for hair removal which 
resulted in $60 \%$ to $80 \%$ reductions after 6 months of multiple treatments (11-13). Laser treatment decreases the percentage of hair regrowth and increases the hairfree period. However, a significant number of patients experience discomfort with the procedure which may fail to treat light-coloured hair. Hence there is a need for study of new approaches which majorly included the development of herbal formulations to treat and prevent the condition and avoid invasive and harmful side effects of laser treatment (14- 19).

Literature search revealed that, selected plant possessed anti-androgenic activity effective against Hirsutism disorder. Hence there is need of screening and assessing the various extracts or biological fractions responsible for Anti- Hirsutism activity. No studies have been reported on molecular docking studies of selected phytoconstituents against selected target of $5 \alpha$ reductase enzyme.

Molecular docking has gained a very important part in drug development process and it is helpful in determining binding affinities or interaction studies of different ligands from natural and synthetic source with that of biological targets. This promoted us to carry out present research work to study the selected phytoconstituents from the plant source of Cyperus Roduntus Linn against $5 \alpha$ reductase enzyme which may aid us to identify and reveal potential ligand from selected chemical constituents which can interact with the target.

Various chemical constituents of Cyperus Rodundus include cyperene, humulen, $\beta$ - selinene, zierone, campholenic aldehyde, $\alpha$-pinene, longiverbenone, $\beta$-vatirenene copaene, and limonene (20).

\section{Materials and Methods Software's}

PyRx 0.8, Biovia Discovery Studio 2019, Molsoft, marvinsketch.

\section{Phytoconstituents}

Cyperene, humulen, $\beta$ - selinene, zierone, campholenic aldehyde, $\alpha$-pinene longiverbenone $\beta$ vatirenene, copaene, and limonene were selected as ligands (21).

\section{Selection of Ligands based on Determination of Drug Likeness Properties}

In our study we have selected cyperene, humulen, $\beta$ - selinene, zierone, campholenic aldehyde, $\alpha$-pinene longiverbenone $\beta$-vatirenene, copaene, limonene as Ligands. The Lipinski's rule of five was followed in order to find out drug-like properties of each ligand. Lipinski's rule aided to compile and determine the data about drug likeness score. Canonical simplified molecular line-entry systems (SMILES) were retrieved from PubChem and used in Molsoft software to acquire data (21).

\section{Preparation of Target Enzyme}

Structure of $5 \alpha$ reductase enzyme was retrieved

from PDB (https://www.rcsb.org/), website in pdb format. There are some water molecules and heteroatoms associated with retrieved protein, hence using Discovery studio 2019, all hetero atoms, water molecules and native ligand were removed to avoid docking interference and saved in the PDB format (21).

\section{Preparation of ligand}

Ligand molecule's 3D structures were retrieved from PubChem (https://pubchem.ncbi.nlm.nih.gov/) in structural data format (SDF). Discovery studio 2019 was used to convert to protein data bank (PDB) format. In current study beta selinene, campholenic Aldehyde, Cyperene, Humulen and Pinene were used as ligands

\section{Determination of Active Sites}

Determination of amino acids in the active site of a protein were carried out by using the Biovia Discovery Studio 2019. The determined of the amino acids in the active site of a protein were further used for analysing docking evaluation results (21).

\section{Molecular Docking}

Molecular Docking was performed using PyRx 0.8. Autodock preferences were obtainedafter the completion of docking, for both ligand and target in PDBQT format. Biovia Discovery Studio 2019 was used for executing docking analysis.From selected ligands and target enzyme the pose for minimum binding energy was selected as best interaction (21).

\section{Results and Discussion}

For selected phytoconstituents Drug likeness properties were calculated. On the basis of adherence to Lipinski's rule of five Ligands and drug candidate compounds have been previously selected. The drug scanning results were calculated and data were presented in Table 1. Molecular docking analysis results for several compounds against $5 \alpha$ reductase Enzyme and its binding energy/Gibbs Energy were presented in Table 2. We investigated Beta Selinene, Campholenic Aldehyde, Cyperene, Humulen and Pinene as potential inhibitors of $5 \alpha$ Reductase Enzyme. The binding energies obtained from docking of $5 \alpha$ reductase enzyme with Beta Selinene, Campholenic Aldehyde, Cyperene, Humulen and Pienene were $-8.3,-6.1,-8.2,-9.6$ and $-6.2 \mathrm{kcal} / \mathrm{mol}$ respectively.

The docking analysis in the present study showed the interaction of several compounds with $5 \alpha$ reductase, ranked by affinity $(\Delta \mathrm{G})$; Humulen $(-9.6)>$ Beta - Selinene $(-8.3)>$ Cyperene $(-8.2)>$ Pinene $(-6.2)>$ Campholenic Aldehyde $(-6.1)$ were the most recommended phytoconstituents found in medicinal plants of Cyperus Roduntus as potential inhibitors of $5 \alpha$ reductase enzyme, which should be explored in future research.Molecular docking analysis of selected Phytoconstituents, selected drugs and its 2D interaction with different amino acids on targets were presented in Table 3 . The binding between $5 \alpha$ reductase enzyme and active ligands as potential inhibitor of $5 \alpha$ reductase enzyme responsible for hair loss is shown in Figure 1. 
Table 1: Drug likeness properties of selected drugs and ligands

\begin{tabular}{|r|l|r|r|r|r|r|}
\hline Sr No. & Name of Ligand & Molecular weight & HBD & HBA & \multicolumn{1}{l|}{ Log P } & Drug Likeness Score(DLS) \\
\hline 1 & Beta Selinene & 204.19 & 0 & 0 & 5.6 & -0.64 \\
\hline 2 & Campholenic Aldehyde & 152.12 & 0 & 1 & 2.93 & -0.74 \\
\hline 3 & Cyperene & 204.19 & 0 & 0 & 5.26 & 0.18 \\
\hline 4 & Humulen & 204.19 & 0 & 0 & 5.53 & -1.68 \\
\hline 5 & Pienene & 136.13 & 0 & 0 & 4.49 & -1.45 \\
\hline
\end{tabular}

Table 2: Pub Chem ID of ligand and binding energy

\begin{tabular}{|c|c|c|c|}
\hline \multirow{2}{*}{ Protein } & Ligands & Pub Chem ID & Binding Energy (kcal/mol) \\
\hline \multirow{3}{*}{$5 \alpha$ reductase Enzyme } & Beta Selinene & 442393 & -8.3 \\
\cline { 2 - 4 } (Pub Chem ID: 7BW1) & Campholenic Aldehyde & 98497 & -6.1 \\
\cline { 2 - 4 } & Cyperene & 99856 & -8.2 \\
\cline { 2 - 4 } & Humulen & 5362885 & -9.6 \\
\hline & Pienene & 6654 & -6.2 \\
\hline
\end{tabular}

Table 3: Molecular docking analysis data of ligands and target

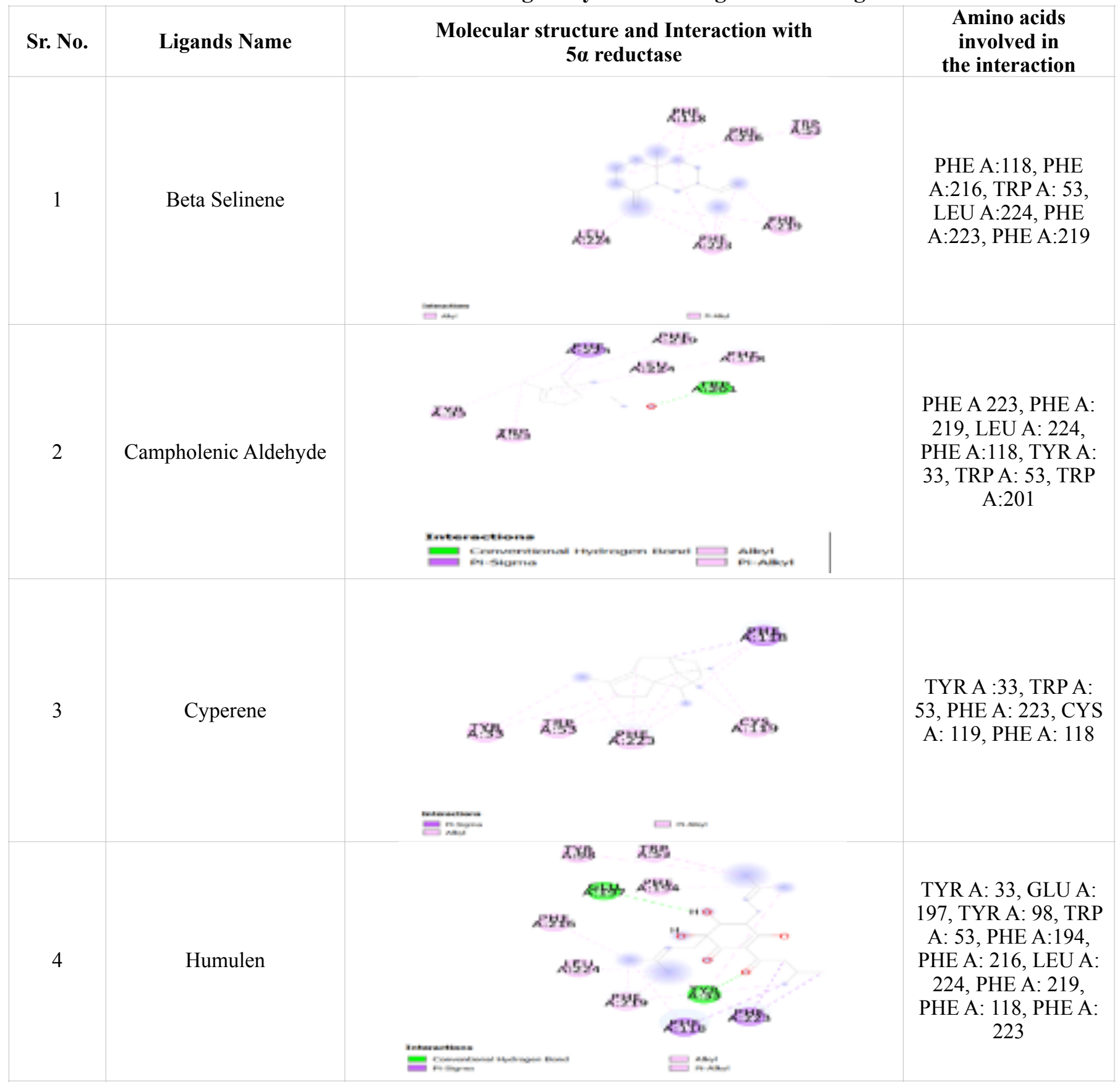



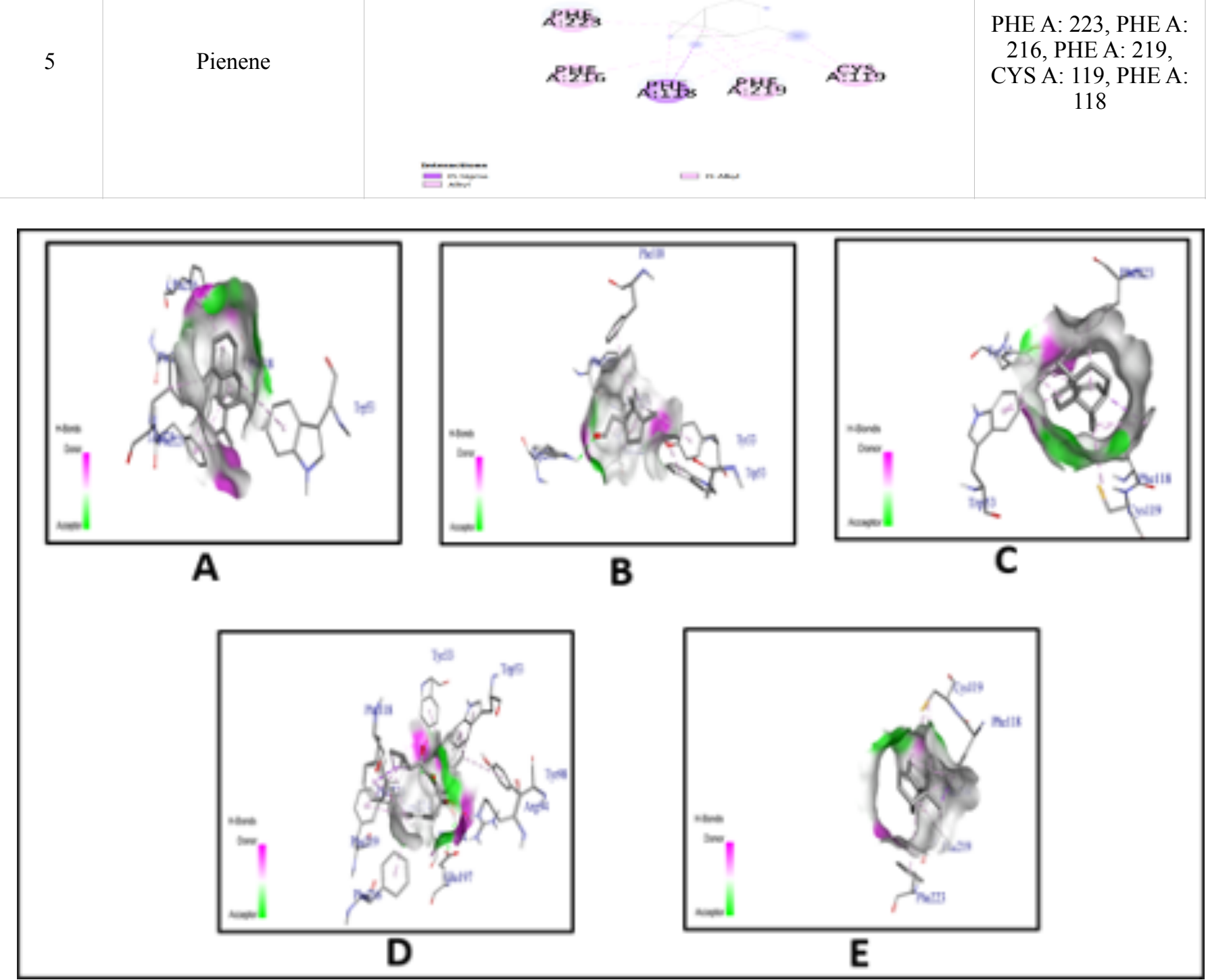

Figure 1: Docking analysis visualization of $5 \alpha$ reductase enzyme with A] Beta Selinene B] Campholenic Aldehyde C] Cyperene D] Humulen E] Pinene

\section{Conclusion}

The present investigation concludes that the molecular docking analysis of selected phytoconstituents with $5 \alpha$ reductase enzyme can to used as potential herbal medicine for Hirsutism disorder. The binding affinity of Humulen is higher than others whereas campholenic aldehyde showed lowest affinity amongst all other ligands. Further studies need to be performed at laboratory level to support results of computational screening of present investigation.

\section{Ackwoledgements}

Authors are thankful to Principal Dr. Sunil S. Jalalpure and Vice Principal Dr. M. B. Patil, KLE College of Pharmacy, Belagavi for their constant support and motivation to carry out research activities. We are also thankful to Mr. Rajkumar S. Patil for his support during computer based screening in our study. We would also like to thank our friend Lakkappa Hanamannavar (IRS) for his inovtional idea for carrying out research work.

\section{References}

1. Mohammed G F. Role of Cyperus rotundus oil in decreasing hair growth. Journal of Intercultural Ethnopharmacology. 2012 July;1(2):111-18.

2. Azziz R, Carmina R, Sawaya M. Idiopathic hirsutism. Endocrine Reviews. 2000 August;21(4):347-62.

3. Hatch R, Robert M D, Rosenfield L. Hirsutism: Implications, etiology, and management. American Journal of Obstetrics and Gynecology. 1981 August;140(7):815-30.

4. Ferriman D, Gallwey J D. Clinical assessment of body hair growth in women. The Journal of Clinical Endocrinology \& Metabolism. 1961 November;21(11):1440-47.

5. Mauvais JP. Regulation of androgen receptor and $5 \alpha$-reductase in the skin of normal and hirsute women. Clinics in Endocrinology and Metabolism. 1986 May;15(2):307-17.

6. Bajpay A, Nainwal RC, Singh D, Tewari S. Medicinal value of Cyperus Rotundus linn: An 
updated review. International Journal of Phytomedicines and Related Industries. 2018 September;10(3):165-70.

7. https://www.pharmatutor.org/articles/ pharmacognosy-of-cyperus-species.

8. Imam H, Zarnigar, Sofi $\mathrm{G}$, Aziz S, Lone A. The incredible benefits of Nagarmotha (Cyperus Rotundus). International Journal of Nutrition, Pharmacology, Neurological Diseases. 2014 January;4(1):23-27.

9. Mohammed G F. Topical Cyperus Rotundus Oil: A new therapeutic modality with comparable efficacy to alexandrite laser photo-epilation. Aesthetic Surgery Journal. 2014 January;34(2):298-305.

10. Trüeb RM. Causes and management of Hypertrichosis. American Journal of Clinical Dermatology. 2012 September;3(9):617-27.

11. Petersen S, Wietelmann $\mathrm{K}$, Evers $\mathrm{T}$, Hüser $\mathrm{N}$, Matevossian E, Doll D. Long-term effects of postoperative razor epilation in pilonidal sinus disease. Disease of the Colon and Rectum. 2009 January;52(1):131-34.

12. Gault D T, Grobbelaar A O, Grover R, Liew S H, Philp B, Clement R M, Kiernan M N. The removal of unwanted hair using a ruby laser. British Journal of Plastic Surgery. 1999 April; 52(3):173-77.

13. Liew SH, Grobbelaar A, Gault DT, Sanders, Green CJ, Linge C. The effect of ruby laser light on ex vivo hair follicles: clinical implications. Annals of Plastic Surgery. 1999 March;42(3):249- 54.

14. Boss WK Jr, Usal H, Thompson RC, Fiorillo MA. A comparison of the long-pulse and short-pulse
Alexandrite laser hair removal systems. Annals of Plastic Surgery. 1999 April;42(4): 381-84.

15. Dierickx CC. Hair removal by lasers and intense pulsed light sources. Seminar on Cutaneous Medicine and Surgery. 2002 December; 19(4): 267-75.

16. Richard O J, Dierickx C C. Laser hair removal. Seminars on Cutaneous Medicine and Surgery. 2002 June;21(2):129-44.

17. Sadick NS, Shaoul J. Hair removal using a combination of conducted radiofrequency and optical energies-An 18-month follow-up. Journal of Cosmetic and Laser Therapy. 2004 May;6(1):21-26.

18. Rao J, Goldman MP. Prospective, comparative evaluation of three laser systems used individually and in combination for axillary hair removal. Dermatologic Surgery. 2005 December;31(12):1671-77.

19. Hovenic W, DeSpain J. Laser hair reduction and removal. Facial Plastic Surgery Clinics of North America. 2011 May;19(2):325-33.

20. Tiwari R, Kumar S. Chemical constituents of the essential oil of Cyperus Rotundus Linn. International journal of Drug Development \& Research. March 2014; 6(2); 57-60.

21. Suryawanshi S S, Patil R S, Pooja B. Screening and assessment of selected alkaloids as potential inhibitors of Covid-19 Protease Enzyme. Journal of Global Trends in Pharmaceutical Sciences. 2020;11 (2):7711-18. 